\title{
Rail Privatisation in Victoria
}

\section{David Greig}

$\mathrm{I}$ n 1999 the previous (Liberal) Victorian government franchised its tram and passenger train services to private operators and sold its freight railway. The decision to privatise rail operations was made in 1997 as part of the government's policy of introducing private sector disciplines and innovation into public transport. The policy followed the successful privatisation of other stateowned infrastructure operations such as the State Electricity Commission.

This article provides some background to rail privatisation in Victoria and highlights some of the unique factors that impacted on the issue. The policy issues are considered in some detail. The paper also describes some of the main features of the privatisation and draws lessons from subsequent experience with the privatisation of the rail systems.

\section{Background}

Melbourne has an extensive commuter train network and the biggest tram network outside East Europe:

- The former Met Trains, now known as M Train and Connex, operate radially from a CBD loop to many parts of greater Melbourne, using 3 and 6 car electric trains.

- The former Met Trams, now M/Tram and Yarra Trams, have a grid of CBD routes and radial extensions to (mainly) inner suburbs - out roughly as far as Melbourne had grown at the end of World War II.

- The tram and train routes overlap somewhat.

Buses, most of them privately operated for many decades and now all private, generally operate at 'right angles' to the railway lines, filling gaps in the rail network and feeding it with passengers. Routes are regulated to largely prevent buses from competing with trams and trains (this policy is discussed later under Unfinished Business).

Public transport takes about half of those, other than pedestrians, going to or from the CBD, but only accounts for about 9 per cent of total Melbourne travel where cars predominate. The following table shows the main train and tram data.

David Greig was a Director in the Transport Reform Unit, Department of Treasury and Finance, Victoria, which managed the rail privatisation. He is now with ACIL Consulting, Melbourne. 
Table 1: Melbourne Passenger Rail Data at Time of Privatisation

\begin{tabular}{|l|c|c|}
\hline \multicolumn{1}{|c|}{1999} & Metropolitan trains & Trams \\
\hline Revenue (fares plus subsidy) \$million & 370 & 129 \\
\hline Passenger journeys per year (million) & 126 & 123 \\
\hline Route kilometres & 366 & 343 \\
\hline Number of carriages/trams & 907 & 476 \\
\hline Number of stations/tram stops & 208 & 1600 \\
\hline
\end{tabular}

There is also a country diesel rail passenger service, V/Line Passenger (revenue $\$ 110$ million per annum at the time of privatisation) which connects Melbourne to a 'crescent' of regional towns including Geelong, Ballarat, Bendigo, Seymour/Albury and Traralgon. A smaller private operator serves Warrnambool. Again private buses, many contracted to V/Line and using its livery, feed traffic but do not compete.

A freight railway, V/Line Freight, which had annual revenue of \$105 million and is now known as Freight Australia, connects the ports, especially Geelong and Portland, to country Victoria and parts of southern NSW. About half its business is grain.

In its first term (1992-96) the Liberal government in Victoria, with its focus on improving the state's finances, cut the size of the public sector including the Public Transport Corporation (PTC), which ran all the train and tram services and some of the buses. It privatised most of the remaining public bus services, installed a new board and senior management at the PTC and reached an agreement with unions, after a showdown, which enabled a halving of PTC staff. The agreement involved not proceeding with certain mooted service cuts, and providing a redundancy package that recognised accrued entitlements.

By the mid 1990s the PTC had substantially improved the reliability of its services, and reduced its costs and subsidies. However international benchmarking showed that performance still fell well short of best practice. Government financial support for passenger rail services was still high (around $\$ 850$ million per annum), and there was consensus among senior management and the then government that further improvement would be difficult to achieve in a large public sector organisation. A decision was made in 1997 to divide the system into several businesses and privatise them - outright sale for the freight railway and 10-15 year private franchises for the passenger services. The transactions were completed in the period from April to August 1999. 


\section{Early Issues in Rail Privatisation}

The 1997 decision to privatise, although triggered by the Melbourne Grand Prix tram strike that year, built on work over the previous 18 months on how the government could go about introducing private sector disciplines and innovation into public transport. This interest followed the successful privatisation of the State Electricity Commission, but from a public policy point of view transport was more complex. Unlike electricity or gas, the government expected to remain actively involved as a purchaser/subsidiser of public transport services. Without subsidies most of them would not run, even if costs were further reduced. Subsidies were considered justified by the external benefits not captured through fares such as reduced congestion and pollution, and providing service to people who cannot drive.

A second complexity was competition. Unlike electricity, where parts of the system (generation and retail) could be made competitive, public transport had monopoly characteristics. Not only was it not sensible to duplicate lines, it also was not sensible to have competing trains on the same line: at busier times the performance of one train in terms of what customers consider important (reliability, punctuality and speed) would often be determined by the performance of the train that preceded it. It was also important to preserve network benefits such as common ticketing and a single comprehensive timetable information service.

The freight railway did not present such problems. Rail and road freight was already deregulated in Victoria, and a straightforward sale was possible, as had already happened successfully in New Zealand, Chile and Argentina. Operating subsidies were not needed or justified. However with the PTC being split up, care was needed to preserve the right for freight trains to operate on passenger tracks and vice versa.

\section{Features of Victorian Passenger Rail Privatisation}

The preceding issues meant that substantial policy work was needed before the government could be confident about proceeding. The competition problem required analysis of periodic re-tendering, which in turn required analysis of vertical integration or separation and of contract length. The government's subsidy role meant that it had to be very clear about what services it was purchasing, and what it would do if performance fell short. And as the work proceeded, it became clear that rolling stock and infrastructure issues, discussed below, would also be complex.

This section summarises how these passenger problems were addressed freight issues are discussed in a subsequent section. The work drew on several branches of economic theory; on experience in the UK, South America and New Zealand; and on experience with other Victorian privatisations. 


\section{Objectives and approach}

The government's transport reform objectives were a progressive improvement in the quality of services, substantially increased patronage, minimisation of long term costs to the taxpayer, transfer of risk to the private sector, and high safety standards.

Whatever was done, it was clear that substantial subsidies would continue to be needed, though declining over time. This reflects unpriced external benefits, the usual justification for urban public transport subsidies, at least until the day when general electronic road pricing (varying by road and time of day) becomes feasible. The pre-privatisation subsidy level was in effect the residual between revenue and expenses; the post privatisation levels emerged from the bidding process.

Outright sale was rejected, except for the freight railway, because the government would have been supporting an entrenched operation indefinitely; without a ready performance benchmark it would have been forced into intrusive cost-plus regulation. Simple management contracts or outsourcing of rail operations were also considered, but not seen as a good basis for investment and innovation. The government decided on a franchising approach - private operators would be subsidised for defined periods, after which there would be retendering.

\section{Competition}

Although lower traffic congestion allows motor vehicles to be stronger competitors for public transport than in large northern hemisphere cities, Melbourne's train and tram systems enjoy a degree of monopoly power, reflecting convenience and restrictive bus regulations (this issue will be discussed later in the 'Unfinished Business' section of the paper). Competitive discipline was thus necessary to ensure improved services and a reduction in subsidies.

Competition on individual lines would not have been effective because of congestion and a loss of network benefits. Periodic re-tendering, of the exclusive right to subsidy on each set of routes, was therefore chosen. In principle others may operate on the routes when there is capacity, but would not attract subsidy. In exchange for the subsidy, operators must commit to defined service standards (outlined below in subsection on 'franchise agreement'). A major criterion in assessing bids for the businesses was minimising the net present value of subsidies.

\section{Horizontal separation and vertical integration}

The radial passenger train network and the nature of the tram network (grid in the CBD, radial outside it) allowed each to be divided in two. A study commissioned by the Transport Reform Unit showed that economies of scale flattened out well below the sizes of the divided businesses (indeed three tram companies were contemplated at one stage). Division into two reduces the prospects of a 
monolithic operator extorting additional concessions from the government over time, provides backup in case of failure by any one operator, and provides yardstick competition (comparative performance data is published quarterly by the government). The smaller country passenger train business was left as one.

A separate railtrack model was considered, but so were the complaints emerging in countries where the model had been adopted. In Sweden, for example, there were concerns that investments were not aligned with operator needs. There were also concerns in the UK that train operating companies did not control enough of their costs, and that the track entity was not always responsive to operator needs such as good service standards and investment to relieve bottlenecks. Subsequent experience has shown that the UK Railtrack model was unsound on both safety and financial grounds, and has confirmed the earlier concerns about incentives for investment.

Melbourne's radial network, with each company largely running on its own lines, lent itself to vertical integration. Competition arguments were not significant as there is little interest from unsubsidised entrants, although an access regime has been imposed which requires spare train paths to be made available if requested. (Vertical separation may however be better in other circumstances, for example, for multi-operator interstate rail freight).

It was thus decided to lease the track, signalling and other infrastructure to the operators (except for country passenger trains, which run on track leased to the freight railway). This avoided the UK problems, but created two others:

- One was shared railway infrastructure in the CBD (for example, the city loop and the main Melbourne stations) and the difficulty in splitting train control and electricity supply and control. Joint leasing was considered, but the commercial strains common in long term joint ventures counted against it. With trains, it was decided to lease some parts of the infrastructure (electrical, and three shared stations) to one operator and some (CBD track, train control, other CBD stations) to the other. Each became a client of the other, with an incentive to cooperate. A similar arrangement with trams was straightforward as the infrastructure is simpler.

- The other problem, of potential opportunism over maintenance, is discussed below (see subsection on 'infrastructure').

\section{Franchise length}

A trade-off was needed over the amount of time that would elapse before retendering. A short period, such as five years, was indicated by competition considerations. A long period, such as 30 or more years, was indicated by investment considerations, as rolling stock typically lasts 30 years with a mid-life refurbishment, and infrastructure 15-60 or more years (for example, shorter for wooden sleepers, medium for electrical overhead, longer for bridges and other structures). 
There is some logic in the periods chosen in different countries:

- the UK, where train operators do not own rolling stock and do not lease infrastructure, chose 7 years for basic franchises and up to 15 in cases where operators indirectly paid for substantial rolling stock replacement or track upgrading. Some of these periods have since been extended;

- Victoria chose 10 years for country passenger trains (which operate on the freight railway's tracks), 12 for trams (simple infrastructure, some rolling stock replacement) and 15 for trains (more complex infrastructure, some rolling stock replacement);

- Argentina chose 30 years, which allows recovery of the high costs of rehabilitating run down railways; and

- the logic also seems to apply to buses, where the interface with the road is benign, vehicle investment needs are more modest than rail, and the market for used vehicles is more liquid - the re-tendering period in various countries is often 10 years (as in Victoria) or less.

\section{Rolling Stock}

One of the benefits of privatisation was seen as avoiding repetition of poor public sector decisions on rolling stock design. For example, new trams were bought in the 1950s using a 1920s design; the newest PTC trams had significant technical problems; the newest PTC trains had component problems that made them less reliable than older trains. The UK approach, under which the rolling stock was sold to three leasing companies (ROSCOs) and train operators had to lease from them, was considered, along with complaints from some UK train operators about rigidity and poor performance incentives in this model.

It was decided that the new franchisees would need to buy the existing rolling stock and make their own arrangements for sale and leaseback, tailored to their own circumstances (for example, financial structures, tax positions). In addition, the franchisees have to replace the oldest 40 per cent of the train and tram fleets (also to be sold and leased back) and refurbish the rest (apart from historic W class trams which heritage groups wanted retained as is and disability groups wanted scrapped).

Arrangements for the return of rolling stock to the government or transfer to a successor franchisee, raised important incentive issues. Franchisees might have been tempted to buy inferior 'lifed' rolling stock likely to deteriorate seriously soon after the first 15 years. The government also had to avoid the possibility of being held hostage by outgoing franchisees aware that the rolling stock was essential to continuity of service. However, there was a risk to financiers in owning rolling stock with a 30-year life and a contract of only half that length.

The solution, after testing the financial markets that had evolved since UK rail privatisation, was to require that the operator arrange for a separate financial entity to buy the new rolling stock and lease it back to the operator. These leases 
will expire approximately three years after the end of the franchise period. The government will take over the leases for the remaining three years, for on-lease to a successor franchisee, and has the option of buying the rolling stock for a predetermined residual value. Alternatively the government may choose to have the rolling stock replaced - three years provides enough lead time. Financial markets were prepared to take the residual value (equivalent to about 30 per cent of the initial value) - new rolling stock can be designed to make it suitable for possible sale elsewhere, but it is likely that the government or successor franchisee will want to renew the leases.

The leases are 'dry'; that is, the operator is responsible for maintenance. The lessor has an interest in the government choosing to renew the lease, and so has an interest in ensuring that the operator maintains the stock according to target condition indices. The government in effect guarantees the lease payments, and takes them on should an operator default, which provides a base for favourable financing terms.

Arrangements for existing rolling stock (now being refurbished) were less complex, as it will be near the end of its economic life by the time of re-tendering.

\section{Infrastructure}

Incentive issues also arose with the infrastructure leased to the franchisees. With heavy, long-life rail infrastructure, an opportunistic franchisee might get away with minimum maintenance expenditure for years before there was a significant deterioration in performance, and even then the punctuality and reliability fines might be less than the saving in maintenance. This was particularly a risk towards the end of the franchise period. On the other hand, detailed government interference in maintenance management would undermine the efficiency and innovation advantages of privatisation.

It was decided to have a belt-and-braces regime: annual asset management plans, an asset condition survey which is periodically updated and produces asset condition indices by class of asset, key performance indicators, and a requirement to maintain an escrow account from which the government will allow money to be released when it is satisfied with maintenance standards. Although this regime allows the government to be somewhat intrusive, it stops short of telling franchisees how to do their maintenance or how much to spend.

\section{Franchise agreement}

The core of the arrangement is the franchise agreement between the operators and the government, which specifies what operators must do in exchange for subsidies. The franchise agreement specifies maximum fares, minimum levels of service, incentives for punctuality and reliability, loading (overcrowding) standards, and general requirements for cleanliness and station security. There was tension between prescription and encouraging innovation. 
The franchise agreements:

- $\quad$ retain current standard and concession fares, plus CPI, and allow special fares below the maxima (CPI-X was rejected as Melbourne's fares are low, subsidies high, and demand is inelastic);

- require the previous frequency of service to be maintained or improved on, with minor variations allowed in service level by route provided overall service is not reduced, and require certain route extensions;

- $\quad$ provide bonuses (or penalties) for good (or poor) punctuality and reliability. Although operators have some natural incentives here, as good service will encourage patronage, they were not seen as strong enough to guarantee the desired standards. This operational performance regime was difficult to design because suitable data had not been kept under public ownership;

- require customer satisfaction surveys to monitor other quality aspects such as cleanliness and personal security. Operator-by-operator survey results, and punctuality and reliability are published quarterly by the Government in Track Record; and

- require customer charters, and compensation to customers when performance falls short.

To preserve network benefits despite having several operators, multi-modal tickets were retained (around 90 per cent of tickets sold may be used on any combination of train, tram and bus) as was a 'one stop shop' timetable information service covering the whole system.

The multi-modal tickets meant that a Revenue Clearing House was necessary. Revenue is allocated according to passenger numbers and passenger kilometres, measured by surveys. Fare evasion was seen as a risk bidders had to manage. They also had to live with the controversial automatic ticketing system - a source of customer dissatisfaction and a constraint on innovation - which was formally commissioned only just before privatisation.

The detailed design of the franchise and revenue arrangements, unlike some other aspects mentioned above, drew heavily from UK experience, with local variations especially for trams where road congestion had to be allowed for. The agreements' stipulations on maximum fares and on maintaining offpeak services, expressed in a widely circulated Passengers' Charter, helps explain the minimal level of public opposition to privatisation.

\section{Risk}

The franchise contracts mainly allocated risk to the party best placed to manage it. Thus operating, cost, financial and most revenue risk were allocated to the private sector, ownership risk was shared, and policy risk was allocated to the government. Some risks were largely allocated to the party best placed to bear them (the government), for example, force majeure and latent defects. This risk allocation was consistent with contract theory, and is consistent with recent 
Victorian government publications on Public Private Partnerships (Department of Treasury and Finance, 2001).

Provisions were made to cover the risk of franchisee default, including government 'step in' to avoid interruption to operations and defined values for government buy-back of assets.

\section{The Initial Outcome}

Most of the bidding interest was from consortia associated with train or tram services in the UK or northern Europe. The UK rail privatisations had helped create a bidder market, and there was strong competition for the four metropolitan businesses. The winning bidders were National Express (a Melbourne train business, the country passenger train business and a tram business), Vivendi/Alstom (the other Melbourne train business) and Transdev/Transfield (the other tram business).

Collectively the bidders committed to subsidy reductions with an NPV of $\$ 1.8$ billion (Transport Reform Unit estimate, compared with a 'public sector comparator' benchmark of what the situation would have been otherwise). This reduction was despite paying for new and refurbished trams and trains and promising various service improvements such as more evening services, upgraded stations and two line extensions. The Victoria Auditor General's Office (2000) provides details of the franchise contracts and payments.

Behind these gains lie:

- Improved efficiency - an average real cost reduction estimated at 34 per cent compared with public sector provision. For example, rosters had been inefficient and 16 per cent of former staff became redundant at the time of the changeover. Fifteen per cent of the fleet had been out of use at any one time, undergoing or waiting for maintenance; best practice is about half that.

- Forecasts of large patronage increases of 40 per cent to 84 per cent over 1215 years (that is, an average of 3.6 per cent per annum, compared with one per cent per annum achieved in the 1990s). If achieved, this would bring patronage to above its highest historic level of the early 1950s, before there was widespread car ownership. Much of the extra patronage was expected to be on off peak or shoulder services, provided at minimum marginal cost. The optimism on patronage was based on judgements about marketing (the PTC did very little), better integration with feeder buses (all the new franchisees are experienced bus operators), better rolling stock, more express services, better real time passenger information, and safer and more attractive stations. The case for optimism was bolstered by the experience of large patronage increases following privatisation elsewhere (for example, UK, Argentina). However, subsequent experience (discussed below) shows some of the optimism to have been misplaced. 
The transition from public to private operation was smooth. The five businesses had already been separated and corporatised under public ownership, and no immediate operational changes were required on day one. There was little public opposition to the change. Public attitudes may have been affected by the tram strike during the 1997 Grand Prix; memories of a strike of several weeks duration about a decade earlier over a minor ticketing matter, with long rows of trams parked in city streets; and a government threat in the mid 1990s to close the system down for months if necessary to overcome industrial opposition to reform. Problems with new ticketing machines, ordered well before the decision to privatise, may have provided a distraction. Victoria's electricity privatisation, which preceded that of rail transport, may have 'prepared' the public for change. Demonstrable improvements to bus services following earlier privatisation of 'Met' bus operations may also have helped. The unions, with memories of many bus drivers willingly accepting redundancy packages, acquiesced to privatisation once similar packages were agreed for rail personnel and an EBA negotiated which preserved entitlements. Finally, the Victorian government learned from poor UK handling of public communication about their rail franchising, and mounted a more professional effort.

In short the government made a financial gain, shed most of the operating, cost, and investment risk, and provided for better services. It also partly shed revenue risk (the extent to which this occurred is discussed later in the 'Subsequent Experience' section of the paper).

\section{The Freight Railway}

The former V/Line Freight is a small railway $(\$ 105 \mathrm{~m}$ per annum revenue at the time of privatisation) carrying grain and other commodities between rural parts of southeast Australia and the ports, plus limited operations elsewhere. Preparation for its privatisation was able to draw on experience in New Zealand, Argentina, South Australia and Tasmania.

The main policy issue concerned the track. The government did not want to sell it, and wanted to ensure that other operators could use it. However the likely bidders, all US-linked, had a strong preference for vertical integration. They saw the 'above rail' and 'below wheel' distinction as artificial, and considered that the opportunity to manage both trains and track can reduce costs and improve performance. The synergies are easier to achieve in-house and harder to achieve across a contractual boundary between two entities. This view was reinforced by dissatisfaction with separate track arrangements in the UK and Sweden.

The government decided to lease the track to the new owner for three consecutive periods of 15 years, with an unstated presumption of renewals beyond that, and to impose an open-access regime. Satisfactory adherence to the access regime is the main criterion to be met for each 15-year renewal. There are no obligations on track maintenance other than for certain lines used by country passenger trains, and unused lines may be handed back to the government after three years (for example, for conversion to bike trails). The access regime 
requires spare train paths, of which there are many, to be made available to other operators for a fee which is largely a pro-rata share of maintenance costs (past capital investment is treated as sunk).

The bidders were all US-based. The railway, now known as Freight Australia, was sold to Rail America for A $\$ 163$ million. The new owner has cut staff by 30 per cent, is recapturing some freight from road operators, has developed some new business (for example, logs and NSW grain) and has replaced the previous losses with an operating profit.

\section{Subsequent Experience}

Experience from the time of privatisation in 1999 has been mostly positive apart from franchisee financial performance. The changeover was smooth and the expected improvements have been or are being made:

- improved reliability, punctuality and customer satisfaction (see Department of Infrastructure Track Record);

- refurbished and new trams and trains;

- increased frequencies, well above the contracted minimum, and better services to sports and other special events;

- $\quad$ some route extensions;

- upgraded stations, station carparks, tram stops and information displays

- upgraded infrastructure;

- $\quad$ traffic lights and other changes to speed up tram services;

- lower off-peak fares on country services

- $\quad$ expanded freight operations.

The contrast with the UK experience is marked - Victoria benefited from the opportunity to learn from that, and does not suffer as much from crowded lines. For recent UK assessments of their experience, see Shadow Strategic Rail Authority (2000) and Department for Transport (2002).

However, patronage increases are well below what the bidders had forecast despite favourable economic conditions, and labour productivity has improved less than some expected. In the government's words (Department of Infrastructure, 2002):

...train and tram operators have experienced less than satisfactory financial performance and are projecting the potential for significant financial losses in coming years.

There have also been indications of dissatisfaction from Freight Australia. The Labor government elected shortly after privatisation was completed has not been happy with what it inherited. 
There appear to be a number of difficulties, including:

- disputes over revenue allocation - past experience with patronage surveys has turned out to be an imperfect indicator of the future, and survey results have been surprisingly variable. There was also an inappropriate governance structure for the Revenue Clearing House. A consequence has been too much focus on shares of the pie, and not enough on increasing its size. Marketing has been unimpressive compared with what was indicated during bidding.

- overly rigid contract management and slow progress until recently in addressing contractual disputes;

- greater and more ingrained fare evasion than some had anticipated, and associated policing problems;

- continuing problems with the ticketing system — problems with the automatic machines, and a contractual dispute with the provider;

- inadequate measurement of infrastructure condition, and little incentive to improve (rather than just maintain and replace) infrastructure (and hence little incentive to participate in longer term transport planning);

- insufficient detail in quality specifications for country track used by passenger trains;

- delays in commissioning a new train control system (covering the whole urban network) by one of the franchisees, affecting the performance of the other one;

- a view that revenue risk is in effect only partly transferred to franchisees, as patronage also depends on wider policies such as road construction and pricing, car park capacity and pricing, and land use;

- a greater net GST impact than franchisees expected, after allowing for sales tax cuts and the GST effect on wages; and

- a dispute over the provisions for track access to competing freight operators.

Some of these have been addressed. In February 2002 the government announced a $\$ 110$ million payment to settle contractual disputes and assist with marketing, in effect taking back some of the revenue risk it thought it had transferred. It has since settled a long standing dispute with the supplier of the ticketing system. Some of the other problems were being addressed as this paper was written: for example, a new Revenue Clearing House structure, finalisation of some rolling stock and fast train negotiations, and an appeal hearing on freight access.

A further 'train and tram franchise review' is under way (Department of Infrastructure, 2002) which presumably will lead to various changes including additional government payments. The review announcement implies that payments may relate to the promotion of patronage growth and to improving operational efficiency. There is a hint at what might have happened in the absence of the review in the wording 
... ensure that the full range of passenger rail train and tram services continue to operate safely and without disruption; ... establish a clear, stable and lasting basis for the future provision of tram and train services in Victoria ...

Subsequent media reports speak of possible mergers and re-tendering (The Age, August 9, 2002).

There are detailed lessons emerging from the issues in the above list. A more general lesson is that bidders may have become too excited near the end of the 'race' and bid too aggressively. Unlike simple privatisations, this 'winner's curse' is a problem for the government which has a continuing relationship with possibly disgruntled partners. And it is a challenge for a government department, whose employees do not face commercial incentives, to manage contracts in a flexible way that protects the government's interests, avoids undue interference, avoids bogging down over small issues, and exploits opportunities for 'win win' improvements.

The franchisees and the government are somewhat stuck with each other, as default and early termination would be unattractive to both. The franchisees will want to renegotiate some of the fundamentals, to see the problems overcome and to start earning better returns. The government will want to avoid a moral hazard problem - it can meet reasonable contractual claims, negotiate to improve shortcomings in the original arrangements, offer increased subsidies for additional improvements in service, and spend on wider objectives (for example, promotion of public transport generally) but, if it goes too far, it will send overly soft signals to the private sector.

\section{Unfinished Business}

The Victorian transport reforms mainly privatised what was there already. Wider policy changes were mainly left for another day. Public transport policies have not kept pace with the changes in Melbourne's development, so it will be difficult to achieve the government's goal of 20 per cent of Melbourne travel being by public transport by the year 2020. Some of the changes that should to be pursued are:

- modification to train and tram services to better align them with demand for example, more service on the busiest tram and train lines, or busiest parts of lines, and less elsewhere (including replacement of low-use services by buses), more express services and fewer stoppers, and investment to ease bottlenecks. Negotiation with franchisees on these issues should be feasible because revenue prospects would be improved;

- a change, long mooted, to the bus subsidy regime, away from cost-plus and towards incentives for passenger growth. This would also encourage better interchange/feeder arrangements with trains; 
- a move to truly competitive re-tendering of Melbourne bus services (due in 2005), combined with flexibility to change the old grid route structure and to shift capacity to new outer suburbs (despite recent improvements some are poorly serviced, while some inner suburbs are relatively over serviced). Ideally a liberalisation of bus regulation would have preceded tram and train franchising, but 10-year bus contracts had been let only four years before. Also the government felt that with rail reform it was biting off enough politically;

- use of jitney type services, intermediate between taxis and buses, on thin routes, similar to 'van' (minibus) services in some US cities; and

- liberalisation of country and school bus services. Some routes are based on long-defunct train lines, some services are nearly empty, no competition with trains is permitted, and franchise renewal has been grandfathered rather than competitively bid.

\section{Conclusion}

The recent Victorian experience confirms the case for privatising freight railways, and shows that carefully designed passenger rail privatisation can produce positive outcomes for customers and governments (assuming the government's subsequent payment increases are modest compared with the originally estimated gains). However the nature of railways, with passenger subsidies because of external benefits, network effects and expensive long-life assets, creates a number of economic policy problems, which should be addressed before proceeding.

A basic problem is how to harness competitive forces while preserving network benefits. Consequential problems are whether and how to divide the system (vertically and horizontally), the issues around periodic re-tendering, and how to get positive interfaces between one operator and another and between operators and their successors. Complex issues with revenue sharing, rolling stock and infrastructure arise here. The other basic problem is how to specify what the travellers and the government are to get in exchange for subsidies, in a way that maintains flexibility to adapt to changing circumstances and to innovate.

Victoria, after considering alternatives, addressed these problems by deciding to split the former PTC horizontally (5 passenger operators and one freight) but not vertically (operators lease their infrastructure); to have competition for the passenger markets (periodic re-tendering) rather than competition within; and to specify the minimum outputs it required (for example, frequency, reliability, punctuality). To support this basic framework, it developed commercial provisions covering multi-modal revenue, rolling stock leases and infrastructure maintenance.

Three years later the outcomes are in many respects pleasing (smooth transition, improved performance, more services, refurbished and new rolling stock, some other upgrades and innovations). Victoria was fortunate in being able to draw on experience in the UK and elsewhere, and then make some advances in the art. Recent difficulties and renegotiations will mean that the gains to the state 
will be less than was expected in 1999, as will the degree of risk transfer, but it appears that they will still be substantial compared with the alternative of continued public sector operation. Other states, facing high subsidies and high renewal costs, would gain by following Victoria, learning from both the better and weaker aspects of its experience.

\section{References}

Auditor General's Office (2000) Report on Ministerial Portfolios, Melbourne.

Department of Infrastructure (quarterly bulletin) Track Record, Melbourne.

Department of Infrastructure (2002), Train and tram franchise review, Melbourne, www.doi.vic.gov.au/transport (accessed 8 August 2002).

Department for Transport (2002), report commissioned from Mercer Management Consulting The GB Rail Industry: In its own words - Problems and Solutions, London.

Department of Treasury and Finance (2001) Partnerships Victoria - Guidance Material (several volumes), Melbourne.

Shadow Strategic Rail Authority (2000) Action to Improve Passenger Rail Services, London.

The author gratefully acknowledges helpful comments by two anonymous referees. 